\title{
Canada needs twice as many palliative specialists
}

Cite as: CMAJ 2017 January 9;189:E34-5. doi: 10.1503/cmaj.109-5354

anada doesn't have enough palliative care doctors to give suffering patients an alternative to assisted death, the Canadian Society of Palliative Care Physicians (CSPCP) warns in a new report.

The group anticipates about 62400 Canadians will request medical assistance to die in 2017. Meeting their palliative care needs will require the equivalent of 170 specialists working 40 hours a week for a year - double the number currently practising in Canada.

"We now have a legal right to access medical aid in dying but we don't have same right to access palliative care," CSPCP President Dr. David Henderson says. Only a third of Canadians currently have access to palliative care, often for just a short time before death. Others face a difficult choice between requesting to die or enduring "needless suffering," he adds.

The access problem is most glaring in remote communities, Henderson says. "When we plotted out people who had received their palliative care competencies, there was one physician in all of northern Canada."

CSPCP is urging the federal government to make good on its promise to invest $\$ 3$ billion in home care and palliative care under a new federal accord. This money should be tied to performance measures and at least some should be exclusively dedicated to palliative care, Henderson says. When funding for home care and palliative care were lumped together in the past, "not much found its way to supporting palliative care," he explains.

CSPCP also wants the Liberal government to reinstate the Canadian Palliative Care Secretariat and support a private member's bill to develop a national framework on palliative care.
"The provinces are all starting to develop their own strategies, so now is the time to standardize before they each develop something different that will be hard to coordinate," says Conservative Member of Parliament Marilyn Gladu, who sponsored Bill C-277.

The bill proposes a framework that would chart a national course for palliative care training, workforce planning, research and performance measurement to close gaps in access. The Canadian Medical Association, Canadian Nurses Association and 38 other groups involved in palliative care have endorsed the bill, which goes to second reading in November.

"We don't even know what kind of care is available across Canada," Gladu says. Meanwhile, "hospitals are full of people who can't get into hospice or other palliative care and the cost of keep- ing people there is four times the cost of doing the same care at home."

Creating a palliative care secretariat to set, monitor and enforce national staffing standards isn't part of the bill, "but I think it's a very good idea," Gladu adds.

In addition to tackling the immediate shortfall of palliative care specialists, CSPCP recommends expanding the core palliative care training provided to all doctors. Most medical schools dedicate fewer than 10 hours to this training, and often doctors don't refer patients for palliative care until it is much too late.

"There are huge gaps in terms of the education family physicians are currently receiving, which is improving, versus their own comfort level when they get out in practice," says Dr. Stephen Singh, co-chair of CSPCP's communication and membership committee. "We'd like to see that

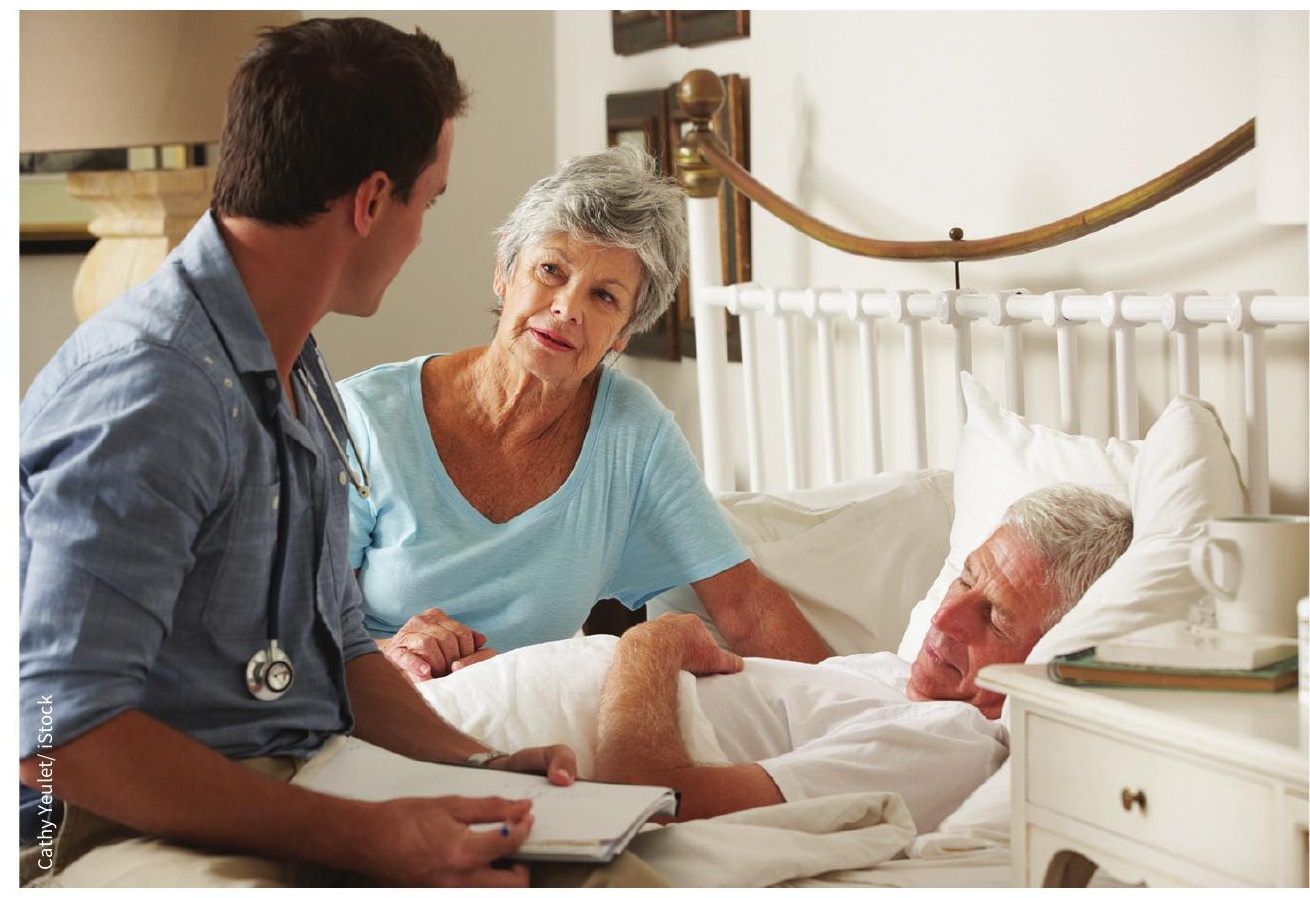

Five out of six patients who request assisted death don't go through with it after receiving palliative care. 
everyone graduating from any residency has the basics."

CSPCP also recommends standardizing coverage for palliative medicines and supplies across Canada. In some cases, "depending on who is doing the prescribing, a drug may or may not be covered," Singh says.

In Nova Scotia, Henderson explains, "you have to be connected with the palliative care service but there are sections of the province that don't have access to a palliative care team and therefore don't get access to the palliative care medication program."

Other provinces only grant coverage if a patient is deemed "sick enough," he says. This creates a vicious cycle: "If you don't have the medication, you get sicker ... if you get your pain under control, you won't qualify for the medications."

Henderson argues that tackling these issues will save governments money, particularly as the number of Canadians over age 65 doubles in the next two decades. Timely palliative care can reduce hospital admissions, lengths of stay and visits to intensive care units, as well as unnecessary tests and procedures. It also increases patient satisfaction and symptom control. Five out of six patients who request assisted death reconsider once they receive palliative care, according to CSPCP's report.

"We see time and time again that people actually start to thrive," Henderson says. "There's a sense that you can die well."

Lauren Vogel, CMAJ 